\section{Evolution of organisational agility: a bibliometric study}

Evolution of organisational agility

\section{School of Economics and Business, University of Ljubljana, Ljubljana, Slovenia Maja Mesko}

Faculty of Management, University of Primorska, Koper, Slovenia and Faculty of Organization Sciences, University of Maribor, Maribor, Slovenia, and Judita Peterlin

School of Economics and Business, University of Ljubljana, Ljubljana, Slovenia

\section{Abstract}

Purpose - This study applies bibliometric analysis to explore the evolution of the research paradigm of agility related to management and organisations.

Design/methodology/approach - Authors prepared a quantitative study of the review of selected articles using co-citation analysis and bibliographic coupling. Based on the bibliometric analyses, the evolution of the agility field (past, present, and future of agility research) was prepared.

Findings - Emergent themes focus on the importance of agility in interpreting organisational responses in the context of issues as diverse as information systems and business intelligence systems, market orientation, strategic alignment and social computing. Future research needs to focus on digitisation in conjunction with informatisation, an important topic for creating a new organisational culture and knowledge management through increased collaboration between humans and machines.

Originality/value - As the authors are aware, this study is one of the first to choose to show the overall development and importance of agility through quantitative bibliometric methods used to assess the value and contribution of scientific productivity and its impact on development.

Keywords Management, Management information systems, Organisational science,

Supply chain management

Paper type Research paper

\section{Introduction}

In the 21st century, organisations are part of rapidly changing economic, business and technological environments. To survive, organisations attempt to respond and adapt to changes or make organisational changes. Namely, flexible organisations have better chances of survival (Vrontis et al., 2021). However, organisational flexibility leads to the question of understanding organisational agility in modern management. In management theory, agility represents the ability to adapt and evolve people and processes in response to rapid and unpredictable changes in the organisation's external and internal environments (Tallon et al., 2019). Since the first mention of agility in 1982 (Brown and

(C) Vasja Roblek, Vlado Dimovski, Maja Mesko and Judita Peterlin. Published by Emerald Publishing Limited. This article is published under the Creative Commons Attribution (CC BY 4.0) licence. Anyone may reproduce, distribute, translate and create derivative works of this article (for both commercial and non-commercial purposes), subject to full attribution to the original publication and authors. The full terms of this licence may be seen at http://creativecommons.org/licences/by/4.0/legalcode

The authors acknowledge that the paper was financially supported by the Slovenian Research Agency, Program P5-0364 - The Impact of Corporate Governance, Organizational Learning, and Knowledge Management on Modern Organization.

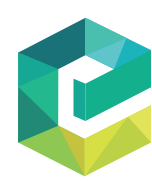

Kybernetes Vol. 51 No. 13, 2022 pp. 119-137 Emerald Publishing Limited 0368-492X 
$\mathrm{K}$

51,13

120

Agnew, 1982, p. 29) and the emergence of the concept of organisational agility in 1991, in the Lehigh Report of the Iacocca Institute (Nagel and Dove, 1991), it has become a crucial factor that shows how competitive the organisation is and whether it allows surviving in more volatile market conditions. Over the years, agility has gained importance in the organisation at the individual, strategic and organisational levels. It presents a complex research field covering different scientific areas such as management, business logistics, marketing, computer science, business information systems and digital transformation. Its core mission is to encourage the organisation to learn about and view changes in their environment as opportunities, respond promptly to them and use them to its advantage, thereby creating a competitive market advantage (Holbeche, 2018).

Representing and understanding the past, present and future drivers of the field of agility, we used three bibliometric approaches to prepare: (1) the method of co-citation analysis enables the identification of existing knowledge and the study of the role and with identifying clusters and connections between articles help us to comprehend the impact of articles on the development of agility in the 1991-2021 period (Small, 1981); (2) as part of a bibliographic coupling, we analysed recent articles in the field of agility (published between 2015-2021). The purpose of the analysis was to explore a topic that will influence future research into agility (Boyack and Klavans, 2010).

The main contribution of bibliometric study is an overview of the evolutionary development and understanding of agility across the period and the knowledge gained from company to survive in disruptive conditions if it tackles organisational adjustments and changes in a timely manner. Which include the digital transformation of business processes, changes in organisational culture and leadership styles and cyber-physical system adoption.

If we summarised the article goals, it should be noted that, based on the analysis of articles using bibliographic methods, the study has achieved the following: (1) identify the groups of the references (i.e. clusters) and (2) discuss the challenges of this literature (i.e. opportunities and difficulties) for future research opportunities on agility. According to the content of the study, the article is intended for researchers, practitioners and students. The article allows them to understand the importance of the agility field and opens up new topics for future research and managers to reflect on its future strategic and developmental direction.

The article consists of the following parts: after the introduction, the second part discussing the theoretical background follows. The third part includes research methodology and describes the methods and sources. The fourth section presents and discusses the results. The last section is the conclusion, which presents the main features and limitations of the research.

\section{Research methodology}

Study design

Bibliometrics is considered a scientific discipline for which several definitions, as well as designations, are known. For example, White and McCain (1989, p. 119) characterise it as "a quantitative study of literature reflecting bibliographies. Its purpose is to explain the evolutionary models of science, technology, and study."

Bibliometrics is considered a truly interdisciplinary research field, which covers almost all academic fields. The methodology includes bibliometric mathematics, social and natural sciences, engineering and other scientific disciplines (Zupic and Cater, 2015). Furthermore, authors such as Palumbo et al. (2021) use different literature review forms in the bibliographic analysis of the literature. Therefore, qualitative methods such as observation, interviews and metadata analysis are also used. In addition, the study is based on the science mapping approach. The approach applies to the generic process of visualisation and domain analysis. The approach allows the scientific mapping of both the scientific groups and the research 
area or, as in our study, a thematic area related to the research questions posed (Chen, 2017). Co-citation analysis and bibliographic coupling (Boyack and Klavans, 2010) were used to represent the bibliographic methods. Applications of science mapping include topic mapping and overlay visualisation of historical, current (new and hot topics) and emerging topics in the field of agility (Waltman and Van Eck, 2012). In selecting the literature, we follow the approaches of authors such as Palumbo et al. (2021). Thus, authors developed a three-step protocol that is presented in Figure 1. The protocol includes (1) data collection: selecting articles published in scientific journals that were indexed in the WOS database; (2) data cleaning: a manual review of article titles and abstracts. Based on their content, we excluded articles inappropriate content; and (3) core analysis includes descriptive statistics and preparing mapping analyses. Figure 2 presents the science mapping workflow. It has consisted of (1) definition of the research design, (2) compilation of bibliometric data, (3) data analysis, (4) visualisation of results and (5) interpretation of results.

\section{Data collection}

In the first research, phase was prepared the collection of articles information. Authors used the SCI and the SSCI WOS database as sources of scientific literature. The database is considered the most trustworthy and thorough source of data (Van Eck and Waltman, 2010; Zupic and Cater, 2015) and is frequently used in bibliometric research on the progress and evaluation of various scientific fields (Waltman and Van Eck, 2012).

The Boolean keyword combination: ((management* AND agility) AND (organisation* OR agility OR flexibility) was used for finding relevant articles. It was no temporal restrictions. The research limitation was set on research and review articles published in English refereed (SCII and SCI) journals.

\section{Data cleaning}

The papers' content (titles, abstracts, keywords and conclusion) was manually reviewed, and papers whose content did not match the research phenomenon were eliminated. From the 1,620 journal papers in WOS, 1,344 papers were chosen for the analysis.
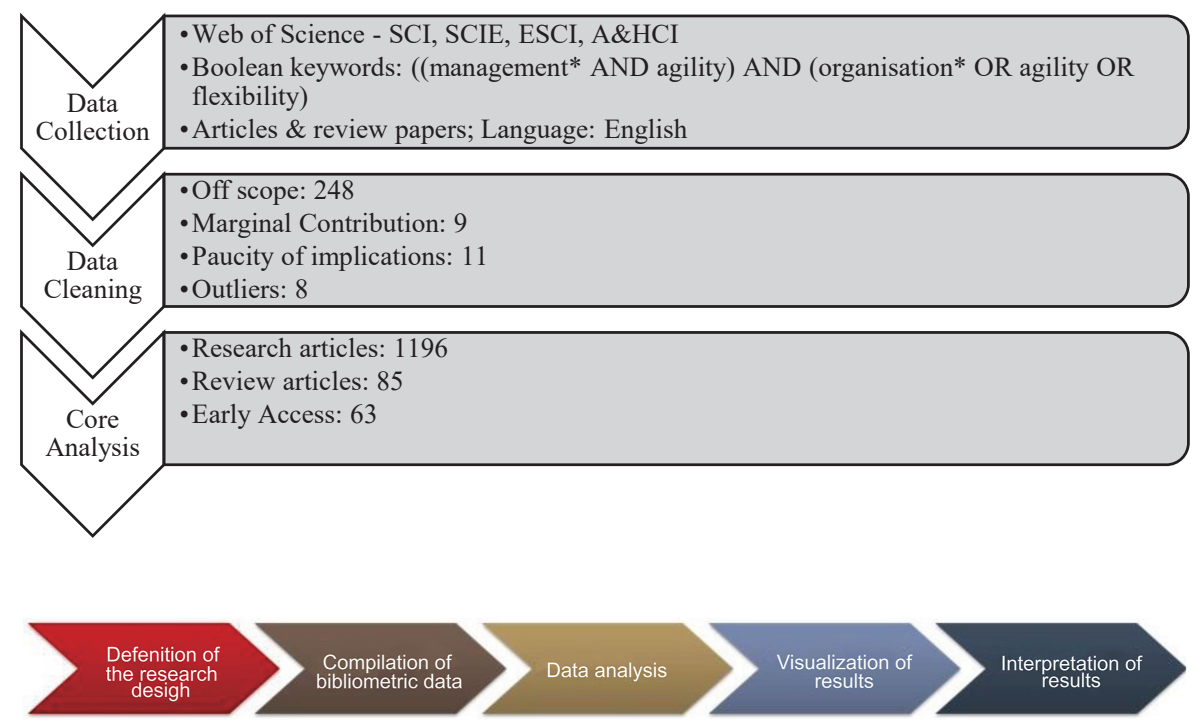

Evolution of organisational agility
Figure 1. Three-step protocol

Figure 2. Science mapping workflow 
$\mathrm{K}$

51,13

122

Core analysis

In the third phase (core analysis), the data of 1,344 articles published between 1992 and July 2021 were exported from WOS. The search was conducted on 1 August 2021. The final search step consisted mainly of a bibliometric analysis based on the similarity visualisation (VOS). The VOS required similar groups of scientific papers based on direct relationships by citation. The bibliometric analysis and mapping central part were performed using a VOSviewer (version 1.6.17) (Van Eck and Waltman, 2010).

\section{Descriptive statistics}

Figure 3 shows the number of articles published from 1992 to July 2021. As shown in Figure 1, the first article was published in 1992, and until 2012, the amount of published articles increased slowly until 2013, when there was a decrease, while after 2013, there was a steep increase in articles. The total citations of all published 1,344 articles are 46,456; without selfcitations, 40,124 , the average per article is 34.57 , and H-Index is 104 . Of the 1,344 articles, 1,177 had at least one citation.

We decided to divide the publication period into four intervals according to the yearly increase of published articles. The first interval was seven years long (1992-1999), the second interval was the shortest and lasted four years (2000-2005), the third interval was the longest, at nine years (2006-2015), and the fourth interval was five years (2016-2021). As can be seen in the last interval, the number of articles published is increasing. Of the 1,344 articles, 34 $(2.53 \%)$ were published between 1992 and 1999, 79 (5.88\%) between 2000 and 2005, 442 between 2006 and 2015 (32.89\%), and 789 (58.71\%) were published in the 2016-2021 period. Thus, the articles were published in 364 journals. The ten journals with the highest numbers of published articles are International Journal Of Production Research (48 articles, 3.57\%), International Journal Of Production Economics (46 articles, 3.42\%), International Journal Of Operations Production Management (41 articles, 3.1\%), Sustainability (37 articles, 2.75\%), Supply Chain Management (28 articles, 2.1\%), Industrial Management Data Systems (27 articles, $2 \%$ ), International Journal Of Information Management (25 articles, 1.86\%),

Figure 3.

Number of papers published from 1992 to 2021

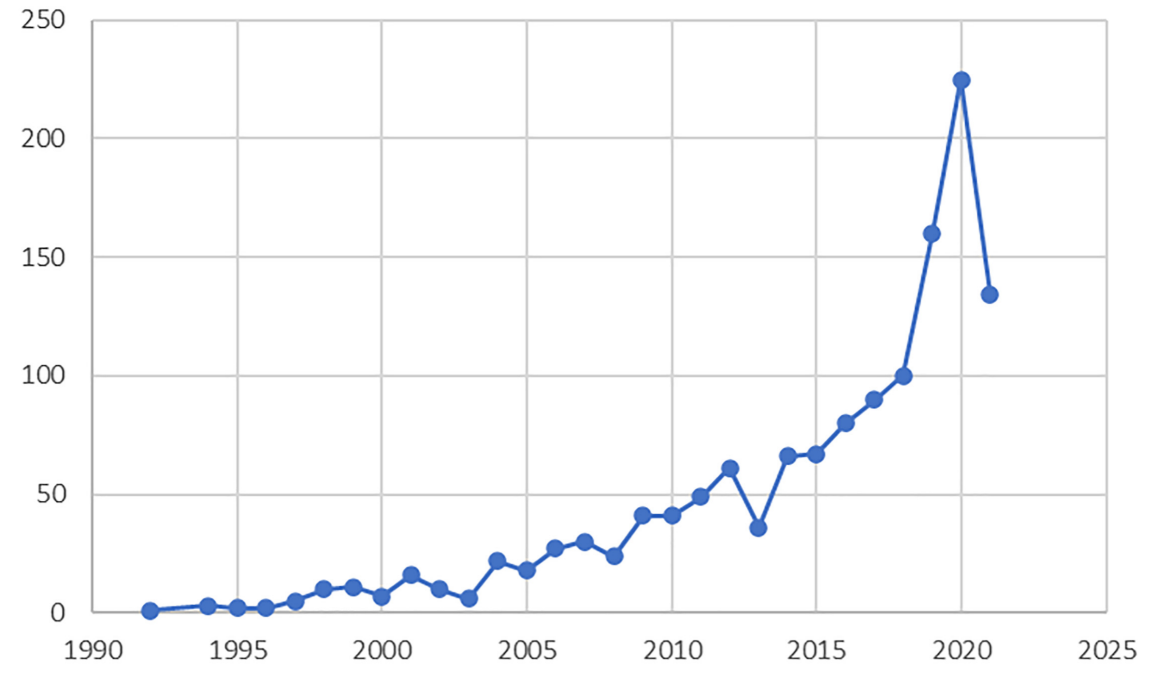

Source(s): WOS 
Journal Of Business Research (25 articles, 1.86\%), Production Planning Control (24 articles, $1.79 \%$ ) and International Journal Of Logistics Management (19 articles, 1.42\%).

\section{Results \\ Bibliometric co-citation analysis}

The co-citation analysis in this study is prepared at the document level. By analysing the documents cited together (co-citation), one can conclude that these works reveal an intellectual relationship between the prominent articles in the discipline and the mapping of the intellectual structure of the discipline (Calabretta et al., 2011). The co-citation method is based on the frequency of two documents from earlier literature being cited in later work, assuming that the more often two documents are cited together, the closer the relationship between them; therefore, they can be considered part of the same research field. However, while this relationship indicates that the documents belong to the general broad research area, they do not necessarily agree with each other.

The co-citation analysis enabled us to find answers on: Who are the primary, peripheral and bridging researchers in the agility field? Furthermore: How has the structure of an agility field developed over time?

\section{Data and procedure}

For the co-citation analysis, 1,344 articles from the database WOS were used (see section descriptive statistics). Articles with ten or more citations were used for a more detailed analysis. VOSviewer software was used to visualise the analysis of the bibliometric agility network. According to Van Eck and Waltman (2010), only the first author's name was included in the analysis to avoid overly cluttered maps. The dataset was analysed with the use of a co-citation analysis with cited references, using articles as analysis items, due to the specificity and the fact that this is a relatively new topic (30 years old). Still, fewer articles of this type were found in development.

Therefore, only articles with ten or more citations were accepted for analysis. From the 56,794 cited references, 726 meet the threshold (secondary articles). It also needs to be mentioned that "co-citation builds on secondary, cited articles and is less sensitive to starting year" (Cerne et al., 2016). Table 1 presents the top twenty references with the greatest link strength, citations and number of links in the agility field. Table 1 also shows that the oldest cited article in the agile field (e.g. the secondary article) was Barney (1991), with 115 citations. The article was published in the Journal of Management. While the oldest articles are secondary articles, Armstrong and Overton (1977) and Fornell and Larcker (1981) were published in the Journal of Marketing Research. These articles deal with research approaches, solutions and methodology (evaluating structural equation models). Considering many citations, we conclude that one of the most important research approaches in agility is quantitative research, including structural equitation models.

\section{Co-citation cluster analysis}

Visualised results of the co-citation analysis are presented in Figure 4. Again, larger node and node labels reflect higher citations (and vice versa), and the colours and adjacent nodes represent the clusters of topic themes.

According to the visual map in Figure 3, four clusters of references co-citation relations emerged. A clusters overview is presented in Table 2.

The first cluster (represented in red in Figure 3) consisted of 347 documents. Depending on the content of the articles, Cluster 1 is labelled as Agility, dynamic capability and information. Researches in the first cluster included an explanation of the vital role of
Evolution of organisational agility
(1) 
$\mathrm{K}$
51,13
References (author, year, publication)

Fornell, C., 1981, J. Marketing Res. V18, P39

Sambamurthy, V. 2003, Mis Quart. V27, P237

Swafford, P.M., 2006, J. of Oper. Man., V24, P170

Teece, D.J., 1997, Strat. Man., V18, P509

Braunscheidel, M.J., 2009, J. Oper. Man., V27, P119

Podsakoff, P.M., 2003, J. App. Psychol., V88, P879

Christopher, M., 2000, Ind. Market Manag., V29, P37

Swafford, P.M., 2008, Int. J. Prod. Econ, V116, P288

Eisenhardt, K.M., 2000, Strat. Man., V.21, P 1105

Overby, E., 2006, Eur. J. Inform. Syst., V15, P120

Yusuf, Y.Y., 1999, Int. J. Prod. Econ., V62, P33

Armstrong, J.S., 1977, J. Marketing Res., V14, P396

Lee, H.L., 2004, Harvard Bus. Rev., V81, P102

Barney, J. 1991, J. Man., V17, P99

Lu, Y., 2011, Mis Quart., V35, P931

Blome, C., 2013, Int. J. Prod. Res. V51, P1295

Table 1.

Top 20 references with the greatest link strength, citations and number of links in the agility field
Sharifi, H., 1999, Int. Prod. Econ., V62, P7

Teece, D.J., 2007, Strat. Man., V28, P1319

Goldman, S.L., 1995, Agile Comp. and Virt. Organisations (book)

Van Hoek, R.I., 2001, Int. J. Oper. Prod. Man., V21, P126

Tallon, P.P., Mis Quart., 2011, V35, P463

Source(s): Created by author based on the VOSviewer analysis

\begin{tabular}{ccc}
$\begin{array}{c}\text { Number of } \\
\text { links }\end{array}$ & Citation & $\begin{array}{c}\text { Total link } \\
\text { strength }\end{array}$ \\
\hline 691 & 200 & 3,685 \\
676 & 216 & 3,646 \\
419 & 149 & 3,367 \\
691 & 179 & 3,355 \\
628 & 119 & 2,855 \\
661 & 144 & 2,852 \\
347 & 137 & 2,818 \\
640 & 121 & 2,801 \\
646 & 121 & 2,801 \\
623 & 119 & 2,317 \\
605 & 123 & 2,237 \\
635 & 99 & 2,147 \\
603 & 94 & 2,120 \\
634 & 115 & 2059 \\
535 & 121 & 2041 \\
575 & 75 & 1905 \\
569 & 104 & 1894 \\
616 & 106 & 1892 \\
574 & 110 & 2,659 \\
544 & 83 & 1803 \\
537 & 92 & 1,635 \\
& &
\end{tabular}

Figure 4 .

Visualisation network of the agility field; co-citation analysis (by the first author; citation $\geq 10$ )

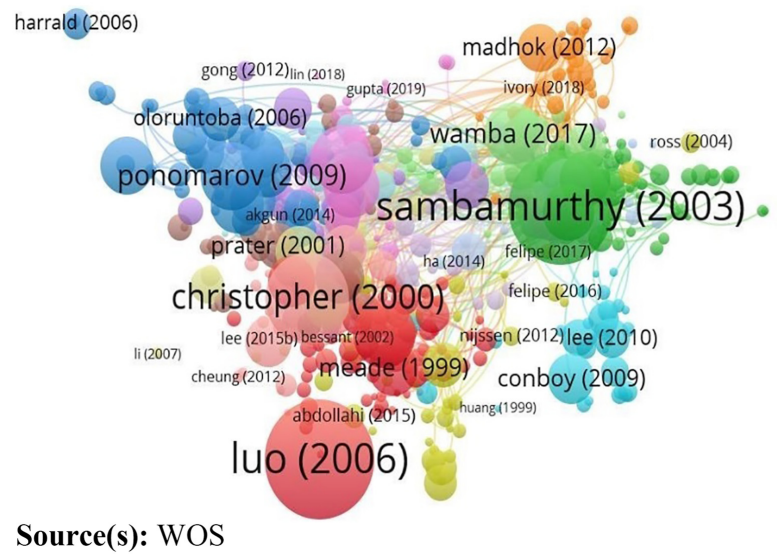

peppaø(2010)

information technology (IT) and to argue that IT investment and dynamic competencies influence firm performance through three organisational competencies (agility, digital options and entrepreneurial vigilance) and strategic processes (capability building, entrepreneurial action and coevolutionary adoption) (Sambamurthy et al., 2003). Overby et al. (2006) defined enterprise agility and the role of IT and digital solutions, analysed the capabilities that support an enterprise's agility and proposed an approach for measuring it. Tallon and Pinsonneault (2011) addressed the importance of competitive views on the link between strategic IT coordination and organisational agility. Lu and Ramamurthy (2011) 


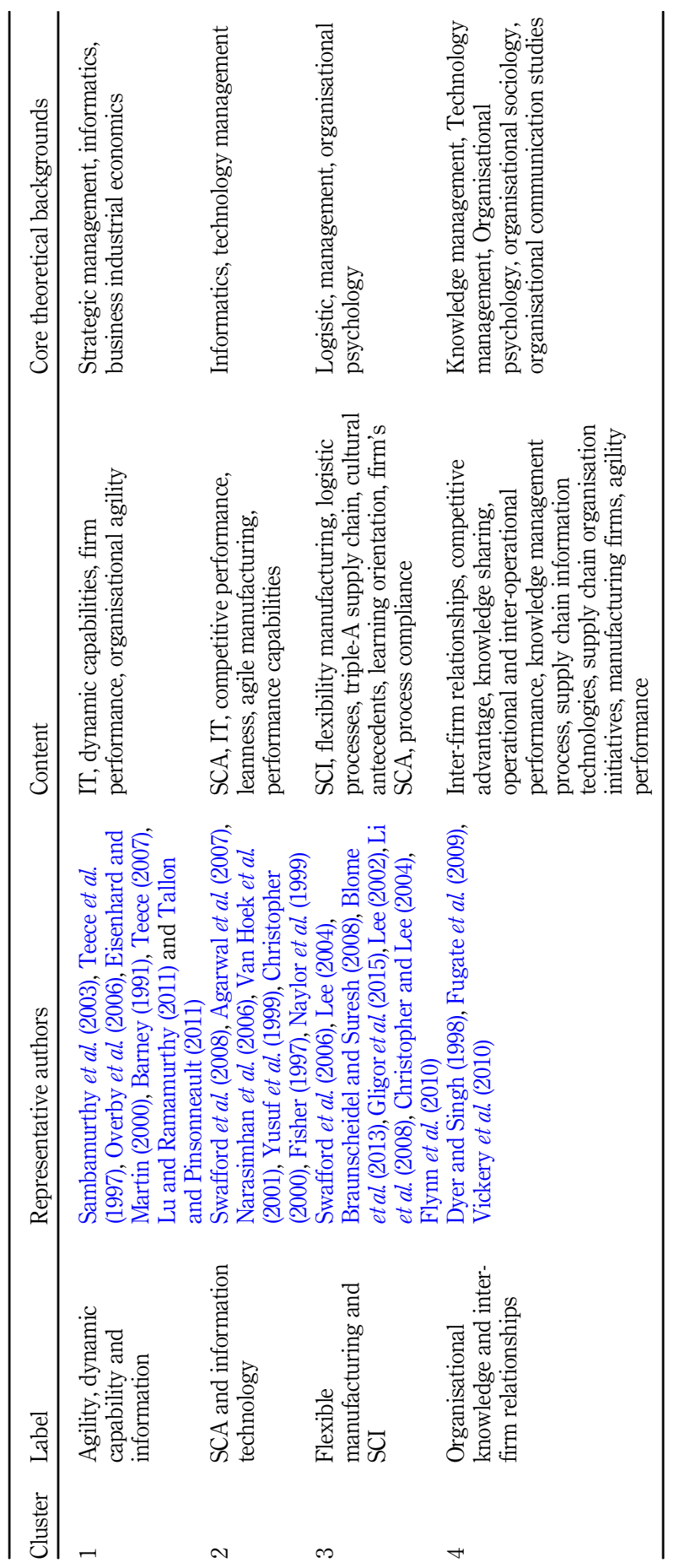

Evolution of organisational agility

125

Table 2. Summary of agility co-citation network (Cluster 1-4) 
$\mathrm{K}$

51,13

126

found that more investment in IT does not lead to greater agility when deployed to enhance and promote IT capabilities; they argue for the conjecture of a contradictory effect of IT on agility. Teece et al. (1997) focus on the dynamic ability to analyse the methods and resources for wealth creation and attainment by private firms operating in the context of rapid technological change. Eisenhard and Martin (2000) defined dynamic capabilities and presented a general view of a firm based on a resource-based view. Barney (1991) examined the relationship between a firm's resources and long-term competitive advantage based on the assumption that strategic resources are distributed heterogeneously across firms and that these differences are stable over time. The article identified four empirical indicators of a firm's potential to create durable competitive advantage: value, rarity, imitability and substitutability. Teece (2007) explained the concept of dynamic capability and its role by outlining the micro-foundations of (sustainable) enterprise performance. Fornell and Larcker (1981) and Podsakoff et al. (2003) address research methodology.

Cluster 2 (green) includes 204 documents. We labelled cluster 2 as supply chain agility (SCA) and IT. This cluster's papers focus on integrating IT that enables firms to increase SCF, leading to greater SCA and improved competitive performance (e.g. Swafford et al., 2008). Agarwal et al. (2007) elaborated insights on the interrelationships of variables that influence SCA. Narasimhan et al. (2006) prepared a literature review in which they discussed leanness and agility in regard to both manufacturing paradigms and performance capabilities. Van Hoek et al. (2001) examined agility in the supply chain (SC). Christopher (2000) focused on the survival of firms in turbulent and volatile markets that affect SC instability. Yusuf et al. (1999) outline agile manufacturing paradigms, identifying the drivers of agile manufacturing and presenting the importance of the competitive advantages that result from changing manufacturing requirements. Naylor et al. (1999) focused on incorporating lean and agile manufacturing paradigms throughout the SC. Fisher (1997) suggested that companies consider the nature of their demand and products before designing a SC.

Cluster 3 (blue) consisted of 196 documents. Cluster 3 can be labelled as flexible manufacturing and SCA. Within the topics discussed in Cluster 3 , it is necessary to mention that Flynn et al. (2010) focused on the importance of supply chain integration (SCI), which is the degree to which a manufacturer strategically collaborates with its SC partners. Li et al. (2008) prepared a literature review in which the need for a comprehensive conceptual model of SCA was identified. In their empirical study, Swafford et al. (2006) determined that the SCA of a firm is directly and positively impacted by the degree of flexibility present in the manufacturing and procurement/sourcing processes of the SC; while it is indirectly impacted by the level of flexibility within its distribution/logistics process. Christopher and Lee (2004) pointed out that better end-to-end transparency is one of the key elements of any SC risk mitigation strategy. Lee (2004) presented a triple-A SC. According to Lee (2004), companies need to provide a fresh attitude and a new culture for their SCs to deliver triple-A performance. Braunscheidel and Suresh (2009) investigated the impact of two cultural antecedents, market orientation and learning orientation and three organisational practices at augmenting the SCA of a firm. Blome et al. (2013) examined the elementary building blocks of SCA constructed as supply-side and demand-side capabilities. They also examine the impact of SCA on operational performance and its mediating role in the relationship between supply-side and demand-side capabilities and performance. Gligor et al. (2015) prepared a study based on archival data about the moderating effects of environmental munificence, dynamism and complexity. The authors (Gligor et al., 2015) determined that SCA can also lead to superior performance for firms operating in stable environments. The study results also provided a better understanding of how FSCA contributes to firm financial performance. Lee (2002) predicted that the right SC strategy should be prepared following the demand and supply uncertainties. The biggest challenge for companies is innovative products, as the demand for them is highly unpredictable and poses the biggest 
challenge to SC processes. Armstrong and Overton (1977) prepared a methodological text about estimating nonresponse bias in mail surveys.

Cluster 4 (yellow) can be labelled as organisational knowledge and inter-firm relationships. The article by Anderson and Gerbing (1988) focused on the use of structural equation modelling. Churchill (1979) proposed a paradigm for developing better measures of marketing constructs. Hair et al. (2014) also wrote a theoretical-methodological article describing the use of partial least squares structural equation modelling. Given these frequently cited methodological articles, we can conclude that empirical methods predominate over qualitative methods for the articles in Cluster 4. Dyer and Singh (1998) formulate a position in which they suggest that a firm's critical resources may transcend its boundaries and be embedded in inter-firm resources and routines. As part of an empirical study, Fugate et al. (2009) investigated the importance of knowledge management processes for operational and inter-operational performance (OPERF). Vickery et al. (2010) empirically examined the role of SC information technologies (SCITs) and SC organisation initiatives (SCOIs) in promoting agility and firm performance in manufacturing firms.

\section{Bibliographic coupling}

For the second bibliographic analysis, we chose bibliographic coupling, which occurs when two articles refer to a common, third article in their bibliographies. This reference indicates the likelihood that both articles deal with a related topic; the "linked strength" of these two articles increases with the more common articles they cite (Kessler, 1963). There has been criticism of the use of bibliographic coupling in cases where authors have used the method to show future searches based on current trends (hot topics, which have been criticised for speculation about the future), but Ferreira (2018) points out that bibliographic coupling remains a useful tool for positioning current contributions to the field despite this criticism. Garfield (2009) pointed out the danger that two articles in the third can refer to a completely unrelated topic and therefore applies the co-citation method to the better indicator of topic similarity. However, Ferreira (2018) believes that the two methods are complementary, as the bibliographic coupling method is "retrospective" and the co-citation method is "prospective".

As part of the preparation of the bibliographic coupling, following the recommendations on the application of this method (Zupic and Cater, 2015), we decided to design a limited time frame of published articles from the previous seven years. As a result, as mentioned above, we found 1,344 articles in the field of agility, of which 633 articles were published between 2015 and 2021.

\section{Bibliographic coupling by articles}

Of the 633 articles, 228 primary articles with at least ten citations were used in the analysis, but the largest group of linked articles consists of 208 articles that were analysed with the goal that the results would contribute to an understanding of the fundamentals of the agility field. The total number of links in all nine clusters was 9,543, with a total link strength of 34,084. Figure 5 shows the fragmented situation of the agility field after 2015 and until today. The circles represent the significant articles/topics and researchers in the research field. As shown in Figure 5, four larger (dominant) fields (circles) have developed alongside five smaller fields. Figure 6 shows a visualisation of the cluster density.

The first cluster (represented in red in Figure 4) consisted of 57 articles. We labelled it IT impact on firm performance. Based on citations, links and link strength, the most important documents in Cluster 1 are Brusset (2016), which prepared a survey of French SC managers. The study's main findings are that their framework applies the dynamic capabilities approach, that visibility through reports or web platforms does not improve agility, and 
$\mathrm{K}$

51,13

\section{8}

Figure 5.

Bibliographic coupling network of the field by documents

Figure 6.

Cluster density visualisation of bibliographic coupling

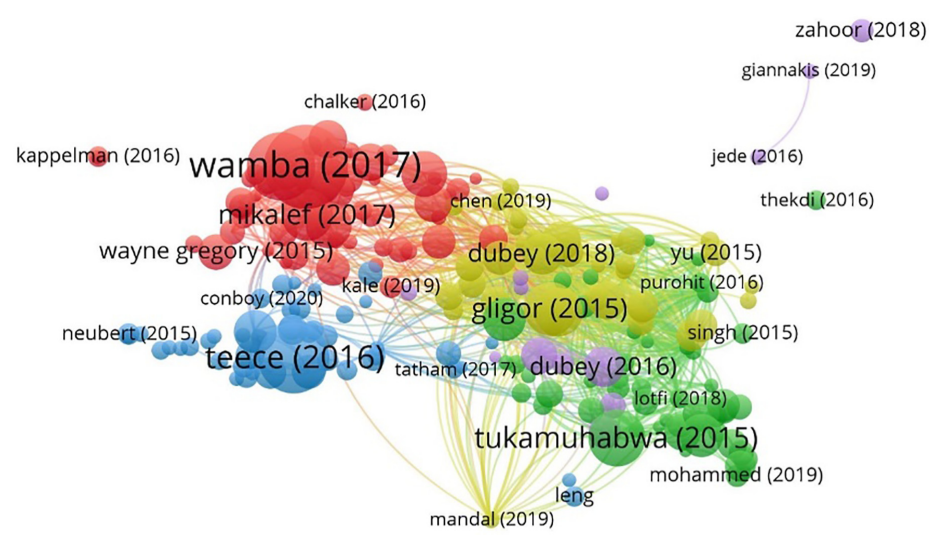

Source(s): WOS Visualisation: Voswiever

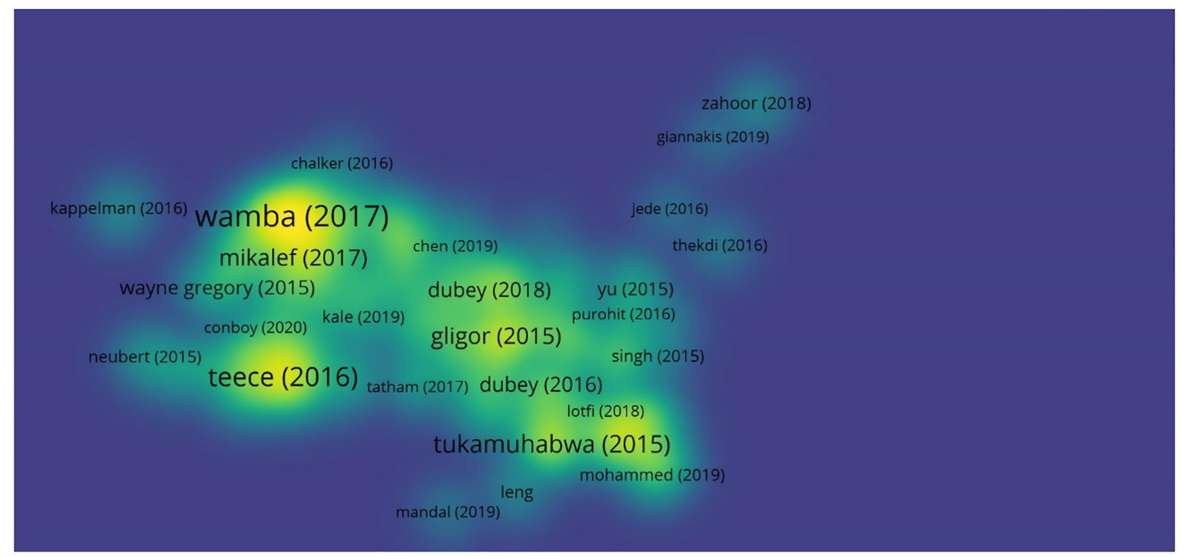

Source(s): WOS Visualisation: Voswiever

that internal and cross-organisational processes improve agility. In the study, Mikalef and Pateli (2017) sought to explain how IT can help build competitive advantage in uncertain environments. As part of their empirical research, they investigated the relationship between competitive performance and IT-enabled dynamic capabilities. Corte-Real et al. (2019) and Mikalef and Pateli (2017) researched the value chain of big data analytics (BDA). In their article, Narayanan et al. (2015) aimed to demonstrate that trust facilitates the effects of collaboration on agility performance, but meanwhile, the indirect effect of collaboration on agility performance through trust is only significant beyond the threshold level of collaboration. Akter et al. (2016) presented a BDA capability (BDAC) model in their study. The model was developed based on firm performance (FPER) and resource-based theory (RBT) and the interconnectedness view of "sociomaterliasm". The study results confirm the impact of BDAC on FPER and the role of corporate strategy alignment.

The second cluster (represented in green in Figure 4) consisted of 47 articles. We labelled the cluster as SC risk management. Based on citations, links and link strength, the most important documents in Cluster 2 are the following. Jajja et al. (2018) determined that 
companies manage $\mathrm{SC}$ risk by using integrative practices with suppliers and customers that boost the performance of agility. Sharma et al. (2017) prepared a review paper about the SCA classification. Gunasekaran et al. (2019) prepared a literature review about agile manufacturing in which authors marked agile manufacturing as a centre of achieving sustainable competitive advantage. Brusset and Teller (2017) presented the SC capabilities, risks and resilience. Study based on the dynamic capabilities approach. Munir et al. (2020) prepared a study about the enabling role of SCI. The study results show that SC risk management partially mediates the relationship between operational performance and internal integration and completely mediates the association between supplier and customer integration and operational performance.

The third cluster (represented in blue in Figure 4) consisted of 44 articles. We labelled it the third cluster business model innovation. Based on citations, links and link strength, the most important articles in Cluster 3 are focused on digital transformation is "an ongoing process of using new digital technologies in everyday organisational life, which recognises agility as the core mechanism for the strategic renewal of an organisation's (1) business model, (2) collaborative approach, and eventually, the (3) culture" (Warner and Wäger, 2019), Conforto et al. (2016) prepared a novel and comprehensive definition of agility, stating that it: (1) combines rapid project planning change and active customer involvement; (2) is a team's ability not only an attribute of "agile methods or practices"; performance may not be a direct result from adopting "agile methods"; and (3) has different intensities and depends on multiple organisation factors. Battistella et al. (2017) prepared a multiple case study about the possibilities of using focused capabilities to cultivate business model agility. Ghezzi and Cavallo (2020) determined that lean startup approaches (LSAs) can be employed as agile methods to enable business model innovation in digital entrepreneurship. Oliva et al. (2019) proposed a model for integrating knowledge management and dynamic capabilities in agile organisations (startups).

The fourth cluster (represented in light green in Figure 4) consisted of 37 articles. We labelled it SC management. Based on citations, links and link strength, the most important documents in Cluster 4 are the following. Wamba et al. (2020) produced an empirical study investigating the moderating effect of environmental dynamics in the context of the performance effects of BDA and SC ambidexterity. Dubey et al. (2019) found that BDAC has a significant and positive effect on SCA and competitive advantage and that organisational flexibility $(\mathrm{OF})$ has a positive and significant moderation effect on the path joining BDAC and SCA. Gligor et al. (2015) empirically determined how FCSA contributes to a firm's financial performance. Finally, Wamba and Akter (2019) found out in their study that SC management, technology and talent are important antecedents of big data-driven SC analytics capability (SCAC).

The fifth cluster (represented in purple in Figure 4) consisted of 10 articles. We labelled it the humanitarian $\mathrm{SC}$ (HSC). Based on citations, links and link strength, the most important documents in cluster 5 are the following. In their study about the HSC, Altay et al. (2018) examined the SCA effects and supply chain resilience (SCR) on performance under the moderating effect on organisational culture. Dubey et al. (2020) prepared an empirical study about the agility in the HSC from the perspective of organisational information processing. Dubey and Gunasekaran (2016) also researched the sustainable HSC design and their differences in commercial SCs; they found the following to be the main characteristics of an HSC network: agility, adaptability and alignment. Schniederjans et al. (2016) prepared an empirically and theoretically validated model depicting the connections between $\mathrm{CC}$ use, collaboration, agility and inter-organisational trust in HSCs. Finally, Oloruntoba and Kovács (2015) prepared a literature review about the evolution of humanitarianism and the environment of humanitarian organisations.
Evolution of organisational agility 
$\mathrm{K}$

51,13

The sixth cluster (represented in light blue in Figure 4) consisted of six articles. We labelled cluster sixth industrial cloud computing. Based on citations, links and link strength, the most important documents in Cluster 6 are the following. Giannakis et al. (2019) introduced comprehensive cloud-based SC management and presented how companies can enhance the responsiveness of their SC. In a systematic literature review, Jede and Teuteberg (2016) presented the main opportunities and risks of using cloud computing in $\mathrm{SC}$ processes, focussing on the $\mathrm{SC}$ aspects of cloud computing sustainability. Morariu et al. (2016) present manufacturing execution systems (MES) virtualisation and shop floor architecture as intermediate manufacturing layers. The article also discusses the benefits that this approach offers to manufacturing companies. In a previous paper, Morariu et al. (2015) prepared an introduction to the virtualisation layer for virtualised MES. In their presentation, the authors mentioned the integration of a manufacturing service bus (MSB) in a cloud environment, a method to scale the private cloud for workload MES intelligently. Finally, Zhou et al. (2016) focused on the comprehensive survey of stateof-the-art approaches for performance optimisations and improvements and the portability management for network $\mathrm{I} / \mathrm{O}$ virtualisation.

The seventh cluster (represented in orange in Figure 4) consisted of three articles. We labelled cluster seventh sustainable SC practices. Based on citations, links and link strength, the most important documents in Cluster 7 are the following. Based on empirical research, Geyi et al. (2020) found that sustainable SC practices allow predicting both sustainable and operational performance. Importantly, the impact of sustainable practices also increases when agile practices mediate relationships. Thekdi and Aven (2016) related key performance management and risk management principles, proposing an enhanced framework to unify thinking of performance and risk. The framework was applied to a public-private partnership case study.

The eighth cluster (represented in brown in Figure 4) consisted of two articles. Cluster 8 can be labelled as organisational learning systems. Based on citations, links and link strength, the most important documents in Cluster 8 focused on the influence of the capabilities of big data analytics management on SC preparedness, alertness and agility. According to the findings, BDA planning, BDA coordination and BDA control are critical enablers of SC preparedness, SC alertness and SCA. In contrast, BDA investment decision making had no significant influence on SC resilience (Mandal, 2019). Mehmood et al. (2017) prepared research about smart societies' personalised ubiquitous teaching and learning systems.

The ninth cluster (represented in pink in Figure 4) consisted of two articles and was labelled as business logistics. Based on citations, links and link strength, the most important documents in Cluster 9 are the following. Pan et al. (2019) studied the design and implementation prospects of smart product service systems in interoperable logistics. In addition, Leng et al. (2021) proposed a novel digital twin-driven joint optimisation approach for warehousing in a large-scale automated high-rise warehouse product-service system. They have developed a digital twin system that allows real-time data aggregation from a physical storage services system and their mapping into a cybernetic model. A common optimisation model is integrated into the digital twin system, how to optimise the allocation of folding packaging and storage systems for warehouse services in a timely manner.

\section{Bibliographic coupling by source}

The following is an analysis of the journals in which articles were published between 2015 and 2021. The analysis considered the threshold of one source article and at least ten citations per article. The result was that the largest group of related articles consisted of 102 journals. After the bibliographic linkage analysis by source, the most relevant journals between 2015 and 2021 were identified (i.e. the journals with the highest number of links and the highest total link strength). The list of journals is shown in Table 3. 


\begin{tabular}{|c|c|c|c|c|}
\hline Source & Documents & Citations & $\begin{array}{l}\text { Total link } \\
\text { strength }\end{array}$ & $\begin{array}{l}\text { Evolution o } \\
\text { organisationa }\end{array}$ \\
\hline International Journal of Production Economics & 21 & 1,050 & 9,800 & \\
\hline Supply Chain Management - An International Journal & 16 & 197 & 6,275 & \\
\hline International Journal of Production Research & 15 & 568 & 5,581 & \\
\hline International Journal of Operations and Production Management & 14 & 321 & 5,309 & \\
\hline Journal of Manufacturing Technology Management & 14 & 186 & 4,911 & 131 \\
\hline Sustainability & 33 & 144 & 4,409 & \\
\hline International Journal of Logistics Management & 12 & 122 & 3,916 & \\
\hline Production Planning and Control & 15 & 236 & 3,251 & \\
\hline Journal of Business Research & 17 & 1,027 & 3,210 & \\
\hline Business Process Management Journal & 10 & 128 & 2,818 & \\
\hline Journal of Enterprise Information Management & 10 & 116 & 2,102 & \\
\hline IEEE Access & 12 & 68 & 244 & Bibliographic coupling \\
\hline Source(s): Created by author, based on the VOSviewer analysis & & & & by source \\
\hline
\end{tabular}

Figure 7 presents a network visualisation. It shows that relatively uniform size of circles of major journals by clusters, with the largest circle containing an International Journal of Production Economics. Circles decrease in the remaining journals, suggesting that agile research has entered other fields to a lesser extent.

\section{Bibliographic coupling by authors}

In the analysis of authors in the agility field, we identified 643 related authors in 501 articles from 2015 to 2021 . We selected the condition that the author has at least one article with ten or more citations. Table 4 shows the authors with the highest number of articles, citations and total link strength per author. The first three most important authors are Gunasekaran and Dubey with nine articles and Childe with six published articles. The first three authors also have the highest total link strength. Key geographical areas covering agility were the USA, England, the People's Republic of China, France and Australia, followed by India as an emerging area.

\section{Discussion and conclusion}

The article focuses on showing a systematic map of the evolution of the agility field. With the help of co-citation analysis, we analysed the agility field in the period from 1991 to 31 July,

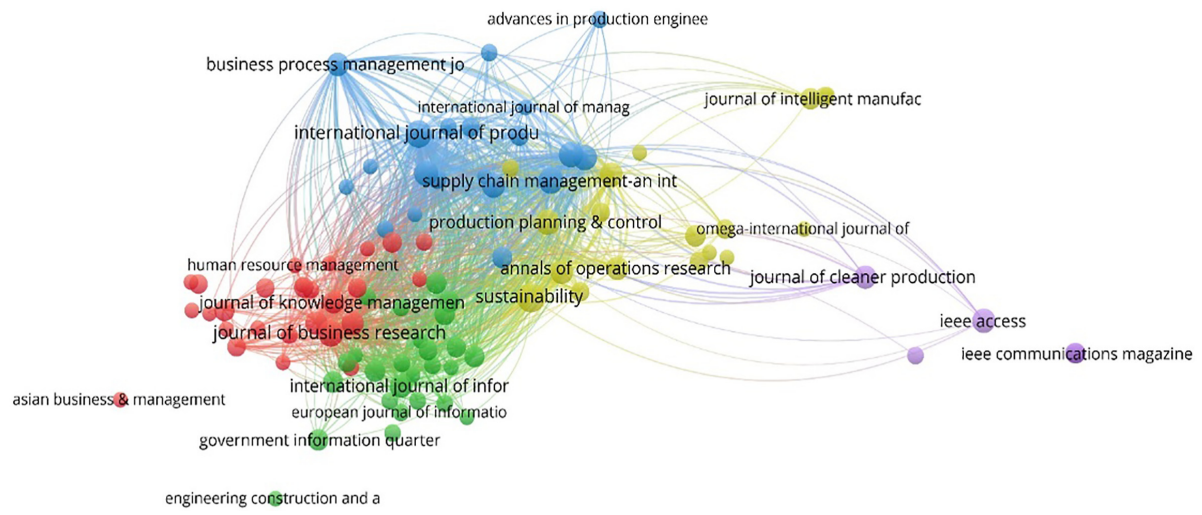

Source(s): WOS Visualisation: Voswiever

Figure 7.

Bibliographic coupling network of the field by journals 
$\mathrm{K}$

51,13

132

2021, and with the aid of bibliographic coupling, we analysed the period from 2015 to 31 July, 2021. It should be noted that the key limitations in the study are related to the selection of scientific articles and review articles and the selection of only the WOS database and the evaluation of the impact on citations covered by SCI and SCII. Thus, the study was limited by article type and impact factor and did not cover all scientific journals and other publications. In our opinion, it will be necessary to prepare a bibliometric analysis in the future, including papers from scientific conferences, chapters from books, books and scientific journals that do not have an impact factor. Another limitation is the determination of thresholds (e.g. number of citations) in the context of bibliometric analysis. The main problem is that this can lead to the elimination of potentially interesting articles.

In the context of the results, based on the overarching visualisation and analysis, we can state that over the years, researchers have found that there is no standard equation that would determine the evolution of an agile company. A company can become increasingly agile, but it will never be concretely agile. Bibliographic coupling analysis shows that agility is an endless process that never ends and should be understood as a continuous improvement of organisational processes and operations. The main assumptions that have evolved over the years and are now among the most important substantive assumptions that help us understand organisational agility are core competencies, competitive advantages and differences based on strategic thinking, innovative approaches, the promotion of change and the constant need to adapt and proactivity of organisations. In doing so, companies are considering the awareness of consumers and competitors, introducing shorter product life cycles, ensuring a faster supply of new products to markets and reducing operating costs. Therefore, it can be concluded that agility enables a company to survive in a changing environment, provided it introduces organisational changes that include changes in leadership, systems adoptions and culture changes (Vrontis et al., 2021; Warner and Wäger, 2019). From the bibliographic coupling analysis, it can be concluded that digital transformation is between the hottest research in the current period and a key factor for the firm's performance and success. Moreover, digitalisation, in conjunction with the increasingly important informatisation, is an important field of research for the future, involving not only technological changes in finished products (e.g. electric cars) and the robotisation of manufacturing processes (both implications for the supply and value chain and future workforce structures, etc.) but also the issue of creating a new corporate culture and knowledge management through increased collaboration between people and machines, as well as the importance of process virtualisation, BDA, cloud computing and artificial intelligence (Holbeche, 2018; Jede and Teuteberg, 2016; Warner and Wäger, 2019).

Future research and development in artificial intelligence, together with CPS, is expected to accelerate the replacement of people in most enterprises (from

Table 4.

Bibliographic coupling: number/citations/total link strength per author (first ten authors

\begin{tabular}{lccc}
\hline Author & Documents & Citations & Total link strength \\
\hline Gunasekaran, A. & 9 & 1,141 & 26,439 \\
Dubey, R. & 9 & 1,141 & 25,600 \\
Childe, S.J. & 6 & 970 & 16,018 \\
Blome, C. & 4 & 297 & 14,263 \\
Fayezi, S. & 4 & 125 & 12,809 \\
Akter, S. & 4 & 779 & 12,415 \\
Gligor, D.M. & 7 & 236 & 11,762 \\
Liu, H. & 3 & 231 & 10,496 \\
O'Loughlin, A. & 3 & 106 & 10,222 \\
Zutsi, A. & 106 & 10,222 \\
Source(s): Created by author, based on the VOSviewer analysis
\end{tabular}


manufacturing, quality control and logistics to strategic decision making). COVID-19 also raises questions about a complex SC, which in many cases is unsustainable and geographically distant from headquarters and subsidiaries. Distance leads to a shortage of materials needed for ongoing production and food supplies in the event of a crisis (El Baz and Ruel, 2021).
Evolution of organisational agility

\section{References}

Agarwal, A., Shankar, R. and Tiwari, M.K. (2007), "Modeling agility of supply chain”, Industrial Marketing Management, Vol. 36 No. 4, pp. 443-457.

Akter, S., Wamba, S.F., Gunasekaran, A., Dubey, R. and Childe, J.S. (2016), "How to improve firm performance using big data analytics capability and business strategy alignment?", International Journal of Production Economics, Vol. 182, pp. 113-131.

Altay, N., Gunasekaran, A., Dubey, R. and Childe, S.J. (2018), "Agility and resilience as antecedents of supply chain performance under moderating effects of organizational culture within the humanitarian setting: a dynamic capability view", Production Planning and Control, Vol. 29 No. 14, pp. 1158-1174.

Anderson, J.C. and Gerbing, D.W. (1988), "Structural equation modeling in practice: a review and recommended two-step approach", Psychological Bulletin, Vol. 103 No. 3, p. 411.

Armstrong, J.S. and Overton, T.S. (1977), "Estimating nonresponse bias in mail surveys", Journal of Marketing Research, Vol. 14 No. 3, pp. 396-402.

Barney, J. (1991), "Firm resources and sustained competitive advantage", Journal of Management, Vol. 17 No. 1, pp. 99-120.

Battistella, C., De Toni, A.F., De Zan, G. and Pessot, E. (2017), "Cultivating business model agility through focused capabilities: a multiple case study”, Journal of Business Research, Vol. 73, pp. 65-82.

Blome, C., Schoenherr, T. and Rexhausen, D. (2013), "Antecedents and enablers of SCA and its effect on performance: a dynamic capabilities perspective", International Journal of Production Research, Vol. 51 No. 4, pp. 1295-1318.

Boyack, K.W. and Klavans, R. (2010), "Co-citation analysis, bibliographic coupling, and direct citation: which citation approach represents the research front most accurately?", Journal of the American Society for Information Science and Technology, Vol. 61 No. 12, pp. 2389-2404.

Braunscheidel, M.J. and Suresh, N. (2009), "The organisational antecedents of a firm's SCA for risk mitigation and response", Journal of Operations Management, Vol. 27 No. 2, pp. 119-140.

Brown, J.L. and Agnew, N.M. (1982), “Corporate agility”, Business Horizons, Vol. 25 No. 2, pp. 29-33.

Brusset, X. (2016), "Does supply chain visibility enhance agility?”, International Journal of Production Economics, Vol. 171, pp. 46-59.

Brusset, X. and Teller, C. (2017), "Supply chain capabilities, risks, and resilience", International Journal of Production Economics, Vol. 184, pp. 59-68.

Calabretta, G., Durisin, B. and Ogliengo, M. (2011), "Uncovering the intellectual structure of research in business ethics: a journey through the history, the classics, and the pillars of Journal of Business Ethics", Journal of Business Ethics, Vol. 104 No. 4, pp. 499-524.

Černe, M., Kaše, R. and Škerlavaj, M. (2016), "Non-technological innovation research: evaluating the intellectual structure and prospects of an emerging field", Scandinavian Journal of Management, Vol. 32 No. 2, pp. 69-85.

Chen, C. (2017), "Science mapping: a systematic review of the literature", Journal of Data and Information Science, Vol. 2 No. 2, pp. 1-40.

Christopher, M. (2000), "The agile supply chain: competing in volatile markets", Industrial Marketing Management, Vol. 29 No. 1, pp. 37-44. 
$\mathrm{K}$

51,13

Christopher, M. and Lee, H. (2004), "Mitigating supply chain risk through improved confidence", International Journal of Physical Distribution and Logistics Management, Vol. 34 No. 5, pp. 388-396.

Churchill, G.A. Jr (1979), “A paradigm for developing better measures of marketing constructs", Journal of Marketing Research, Vol. 16 No. 1, pp. 64-73.

Conforto, E.C., Amaral, D.C., da Silva, S.L., Di Felippo, A. and Kamikawachi, D.S.L. (2016), "The agility construct on project management theory", International Journal of Project Management, Vol. 34 No. 4, pp. 660-674.

Côrte-Real, N., Ruivo, P., Oliveira, T. and Popovič, A. (2019), "Unlocking the drivers of big data analytics value in firms", Journal of Business Research, Vol. 97, pp. 160-173.

Dubey, R., Bryde, D.J., Foropon, C., Graham, G., Giannakis, M. and Mishra, D.B. (2020), “Agility in humanitarian supply chain: an organizational information processing perspective and relational view", Annals of Operations Research, pp. 1-21 (in press).

Dubey, R. and Gunasekaran, A. (2016), "The sustainable humanitarian supply chain design: agility, adaptability and alignment", International Journal of Logistics Research and Applications, Vol. 19 No. 1, pp. 62-82.

Dubey, R., Gunasekaran, A. and Childe, S.J. (2019), "Big data analytics capability in SCA: the moderating effect of organisational flexibility", Management Decision, Vol. 7 No. 8, pp. 2092-2112.

Dyer, J.H. and Singh, H. (1998), "The relational view: cooperative strategy and sources of interorganizational competitive advantage", Academy of Management Review, Vol. 23 No. 4, pp. 660-679.

Eisenhardt, K.M. and Martin, J.A. (2000), "Dynamic capabilities: what are they?”, Strategic Management Journal, Vol. 21 Nos 10-11, pp. 1105-1121.

El Baz, J. and Ruel, S. (2021), "Can supply chain risk management practices mitigate the disruption impacts on supply chains' resilience and robustness? Evidence from an empirical survey in a COVID-19 outbreak era”, International Journal of Production Economics, Vol. 233, 107972.

Ferreira, F.A. (2018), "Mapping the field of arts-based management: bibliographic coupling and co-citation analyses", Journal of Business Research, Vol. 85, pp. 348-357.

Fisher, M.L. (1997), "What is the right supply chain for your product?", Harvard Business Review, Vol. 75, pp. 105-117.

Flynn, B.B., Huo, B. and Zhao, X. (2010), "The impact of SCI on performance: a contingency and configuration approach", Journal of Operations Management, Vol. 28 No. 1, pp. 58-71.

Fornell, C. and Larcker, D.F. (1981), "Evaluating structural equation models with unobservable variables and measurement error", Journal of Marketing Research, Vol. 18 No. 1, pp. 39-50.

Fugate, B.S., Stank, T.P. and Mentzer, J.T. (2009), "Linking improved knowledge management to operational and organizational performance”, Journal of Operations Management, Vol. 27 No. 3, pp. 247-264.

Garfield, E. (2009), "From the science of science to Scientometrics visualising the history of science with HistCite software", Journal of Informetrics, Vol. 3 No. 3, pp. 173-179.

Geyi, G.D.Y., Yusuf, Y., Menhat, M.S., Abubakar, T. and Ogbuke, N.J. (2020), “Agile capabilities as necessary conditions for maximising sustainable supply chain performance: an empirical investigation", International Journal of Production Economics, Vol. 222, 107501.

Ghezzi, A. and Cavallo, A. (2020), "Agile business model innovation in digital entrepreneurship: lean startup approaches”, Journal of Business Research, Vol. 110, pp. 519-537.

Giannakis, M., Spanaki, K. and Dubey, R. (2019), “A cloud-based supply chain management system: effects on supply chain responsiveness", Journal of Enterprise Information Management, Vol. 32 No. 4, pp. 585-607.

Gligor, D.M., Esmark, C.L. and Holcomb, M.C. (2015), "Performance outcomes of SCA: when should you be agile?”, Journal of Operations Management, Vol. 33, pp. 71-82. 
Gunasekaran, A., Yusuf, Y.Y., Adeleye, E.O., Papadopoulos, T., Kovvuri, D. and Geyi, D.A.G. (2019), "Agile manufacturing: an evolutionary review of practices", International Journal of Production Research, Vol. 57 Nos 15-16, pp. 5154-5174.

Hair, J. Jr, Sarstedt, M.F.K., Hopkins, L.J. and Kuppelwieser, V.G. (2014), "Partial least squares structural equation modeling (PLS-SEM): an emerging tool in business research", European Business Review, Vol. 26 No. 2, pp. 106-121.

Holbeche, L. (2018), The Agile Organisation: How to Build an Engaged, Innovative and Resilient Business, Kogan Page Publishers, London, EN.

Jajja, M.S.S., Chatha, K.A. and Farooq, S. (2018), "Impact of supply chain risk on agility performance: mediating role of SCI", International Journal of Production Economics, Vol. 205, pp. 118-138.

Jede, A. and Teuteberg, F. (2016), "Towards cloud-based supply chain processes: designing a reference model and elements of a research agenda", The International Journal of Logistics Management, Vol. 27 No. 2, pp. 438-462.

Kessler, M.M. (1963), "Bibliographic coupling between scientific papers", American Documentation, Vol. 14 No. 1, pp. 10-25.

Lee, H.L. (2002), "Aligning supply chain strategies with product uncertainties", California Management Review, Vol. 44 No. 3, pp. 105-119.

Lee, H.L. (2004), “The triple-A supply chain”, Harvard Business Review, Vol. 82 No. 10, pp. 102-113.

Leng, J., Yan, D., Liu, Q., Zhang, H., Zhao, G., Wei, L. and Chen, X. (2021), "Digital twin- driven joint optimisation of packing and storage assignment in large-scale automated high-rise warehouse product-service system", International Journal of Computer Integrated Manufacturing, Vol. 34 Nos 7/8, pp. 783-800.

Li, X., Chung, C., Goldsby, T.J. and Holsapple, C.W. (2008), "A unified model of supply chain agility: the work-design perspective", The International Journal of Logistics Management, Vol. 19 No. 3, pp. 408-435.

$\mathrm{Lu}, \mathrm{Y}$. and Ramamurthy, K. (2011), "Understanding the link between information technology capability and organisational agility: an empirical examination”, MIS Quarterly, Vol. 35 No. 4, pp. 931-954.

Mandal, S. (2019), "The influence of big data analytics management capabilities on supply chain preparedness, alertness and agility: an empirical investigation”, Information Technology and People, Vol. 32 No. 2, pp. 297-318.

Mehmood, R., Alam, F., Albogami, N.N., Katib, I., Albeshri, A. and Altowaijri, S.M. (2017), "UTiLearn: a personalised ubiquitous teaching and learning system for smart societies", IEEE Access, Vol. 5, pp. 2615-2635.

Mikalef, P. and Pateli, A. (2017), "Information technology-enabled dynamic capabilities and their indirect effect on competitive performance: findings from PLS-SEM and fsQCA", Journal of Business Research, Vol. 70, pp. 1-16.

Morariu, O., Borangiu, T. and Raileanu, S. (2015), "vMES: virtualisation aware manufacturing execution system", Computers in Industry, Vol. 67, pp. 27-37.

Morariu, O., Morariu, C. and Borangiu, T. (2016), "Shop-floor resource virtualisation layer with private cloud support", Journal of Intelligent Manufacturing, Vol. 27 No. 2, pp. 447-462.

Munir, M., Jajja, M.S.S., Chatha, K.A. and Farooq, S. (2020), "Supply chain risk management and operational performance: the enabling role of supply chain integration", International Journal of Production Economics, Vol. 227, 107667.

Nagel, R.N. and Dove, R. (1991), 21st Century Manufacturing Enterprise Strategy: An Industry- Led View, Iacocca Institute, Lehigh University, Bethlehem.

Narasimhan, R., Swink, M. and Kim, S.W. (2006), "Disentangling leanness and agility: an empirical investigation", Journal of Operations Management, Vol. 24 No. 5, pp. 440-457.
Evolution of organisational agility 
$\mathrm{K}$

51,13

Narayanan, S., Narasimhan, R. and Schoenherr, T. (2015), "Assessing the contingent effects of collaboration on agility performance in buyer-supplier relationships", Journal of Operations Management, Vol. 33, pp. 140-154.

Naylor, J.B., Naim, M.M. and Berry, D. (1999), "Leagility: integrating the lean and agile manufacturing paradigms in the total supply chain", International Journal of Production Economics, Vol. 62 Nos 1-2, pp. 107-118.

Oliva, F.L., Couto, M.H.G., Santos, R.F. and Bresciani, S. (2019), "The integration between knowledge management and dynamic capabilities in agile organisations", Management Decision, Vol. 57 No. 8, pp. 1960-1979.

Oloruntoba, R. and Kovács, G. (2015), "A commentary on agility in humanitarian aid supply chains", Supply Chain Management, Vol. 20 No. 6, pp. 708-716.

Overby, E., Bharadwaj, A. and Sambamurthy, V. (2006), "Enterprise agility and the enabling role of information technology", European Journal of Information Systems, Vol. 15 No. 2, pp. 120-131.

Palumbo, R., Manesh, M.F., Pellegrini, M., Caputo, A. and Flamini, G. (2021), "Organising a sustainable smart urban ecosystem: perspectives and insights from a bibliometric analysis and literature review", Journal of Cleaner Production, Vol. 97, 126622.

Pan, S., Zhong, R.Y. and Qu, T. (2019), "Smart product-service systems in interoperable logistics: design and implementation prospects", Advanced Engineering Informatics, Vol. 42, 100996.

Podsakoff, P.M., MacKenzie, S.B., Lee, J.Y. and Podsakoff, N.P. (2003), "Common method biases in behavioral research: a critical review of the literature and recommended remedies", Journal of Applied Psychology, Vol. 88 No. 5, p. 879.

Sambamurthy, V., Bharadwaj, A. and Grover, V. (2003), "Shaping agility through digital options: reconceptualising the role of information technology in contemporary firms", MIS Quarterly, Vol. 27 No. 2, pp. 237-263.

Schniederjans, D.G., Ozpolat, K. and Chen, Y. (2016), "Humanitarian supply chain use of cloud computing”, Supply Chain Management, Vol. 21 No. 5, pp. 569-588.

Sharma, N., Sahay, B.S., Shankar, R. and Sarma, P.R.S. (2017), "SCA: review, classification and synthesis", International Journal of Logistics Research and Applications, Vol. 20 No. 6, pp. 532-559.

Small, H. (1981), "The relationship of information science to the social sciences: a co-citation analysis", Information Processing and Management, Vol. 17, pp. 39-50.

Swafford, P.M., Ghosh, S. and Murthy, N. (2006), "The antecedents of supply chain agility of a firm: scale development and model testing", Journal of Operations Management, Vol. 24 No. 2, pp. 170-188.

Swafford, P.M., Ghosh, S. and Murthy, N. (2008), "Achieving SCA through IT integration and flexibility", International Journal of Production Economics, Vol. 116 No. 2, pp. 288-297.

Tallon, P.P. and Pinsonneault, A. (2011), "Competing perspectives on the link between strategic information technology alignment and organisational agility: insights from a mediation model", MIS Quarterly, Vol. 35 No. 2, pp. 463-486.

Tallon, P.P., Queiroz, M., Coltman, T. and Sharma, R. (2019), "Information technology and the search for organisational agility: a systematic review with future research possibilities", The Journal of Strategic Information Systems, Vol. 28 No. 2, pp. 218-237.

Teece, D.J. (2007), "Explicating dynamic capabilities: the nature and microfoundations of (sustainable) enterprise performance", Strategic Management Journal, Vol. 28 No. 13, pp. 1319-1350.

Teece, D.J., Pisano, G. and Shuen, A. (1997), "Dynamic capabilities and strategic management", Strategic Management Journal, Vol. 18 No. 7, pp. 509-533.

Thekdi, S. and Aven, T. (2016), "An enhanced data-analytic framework for integrating risk management and performance management", Reliability Engineering and System Safety, Vol. 156, pp. 277-287. 
Van Eck, N.J. and Waltman, L. (2010), "Software survey: VOSviewer, a computer program for bibliometric mapping”, Scientometrics, Vol. 84 No. 2, pp. 523-538.

Van Hoek, R.I., Harrison, A. and Christopher, M. (2001), "Measuring agile capabilities in the supply chain", International Journal of Operations and Production Management, Vol. 21 Nos 1-2, pp. 126-148.

Vickery, S.K., Droge, C., Setia, P. and Sambamurthy, V. (2010), "Supply chain information technologies and organisational initiatives: complementary versus independent effects on agility and firm performance”, International Journal of Production Research, Vol. 48 No. 23, pp. 7025-7042.

Vrontis, D., Morea, D., Basile, G., Bonacci, I. and Mazzitelli, A. (2021), "Consequences of technology and social innovation on traditional business model", Technological Forecasting and Social Change, Vol. 170, 120877.

Waltman, L. and Van Eck, N.J. (2012), "A new methodology for constructing a publication-level classification system of science", Journal of the American Society for Information Science and Technology, Vol. 63 No. 12, pp. 2378-2392.

Wamba, S.F. and Akter, S. (2019), "Understanding supply chain analytics capabilities and agility for data-rich environments", International Journal of Operations and Production Management, Vol. 39 Nos 6/7/8, pp. 887-912.

Wamba, S.F., Dubey, R., Gunasekaran, A. and Akter, S. (2020), "The performance effects of big data analytics and supply chain ambidexterity: the moderating effect of environmental dynamism", International Journal of Production Economics, Vol. 222, 107498.

Warner, K.S. and Wäger, M. (2019), "Building dynamic capabilities for digital transformation: an ongoing process of strategic renewal”, Long Range Planning, Vol. 52 No. 3, pp. 326-349.

White, H.D. and McCain, K.W. (1989), "Bibliometrics", Annual Review of Information Science and Technology, Vol. 24, pp. 119-186.

Yusuf, Y.Y., Sarhadi, M. and Gunasekaran, A. (1999), “Agile manufacturing: the drivers, concepts and attributes", International Journal of Production Economics, Vol. 62 Nos 1-2, pp. 33-43.

Zhou, F.F., Ma, R.H., Li, J., Chen, L.X., Qiu, W.D. and Guan, H.B. (2016), "Optimisations for high performance network virtualisation", Journal of Computer Science and Technology, Vol. 31 No. 1, pp. 107-116.

Zupic, I. and Čater, T. (2015), "Bibliometric methods in management and organisation", Organizational Research Methods, Vol. 18 No. 3, pp. 429-472.

\section{About the authors}

Vasja Roblek is a Ph.D. student at the Faculty of Organization Studies in Novo Mesto. He earned his M.Sc. from the University of Primorska; his research interests include management, knowledge management, information management and sustainability.

Vlado Dimovski is a full professor in management and organisation studies at the University of Ljubljana School of Economics and Business. He earned his Ph.D. from Cleveland State University; his research interests include multiple intelligences, knowledge management and age management.

Maja Mesko is a full professor in management at the University of Primorska, Faculty of Management. Koper and full professor in human resource management at the University of Maribor, Faculty of Organization Science, Kranj. She earned her Ph.D. from the University of Ljubljana; her research interests include psychology in management, occupational health and management.

Judita Peterlin is an associate professor in management and organisation studies at the University of Ljubljana School of Economics and Business. She earned her Ph.D. from the University of Ljubljana; her research interests include multiple intelligences, social innovation and sustainable leadership. Judita Peterlin is the corresponding author and can be contacted at: judita.peterlin@ef.uni-lj.si

For instructions on how to order reprints of this article, please visit our website:

www.emeraldgrouppublishing.com/licensing/reprints.htm

Or contact us for further details: permissions@emeraldinsight.com
Evolution of organisational agility 